\title{
¿Cómo se hace uno justo? (De Trinitate VIII)
}

Tratando de buscar los fundamentos a una doctrina de la gracia, es necesario iniciar por aquello que puede fundamentarla. Ordinariamente en teología agustiniana -especialmente en teología de la gracia - no se ha tenido en cuenta este libro VIII De Trinitate. A lo sumo se ha hablado de ello, aunque en breve, en la ética agustiniana o en la moral, pero sin profundizar en él. Parece como si se tuviera miedo a estos textos tan claros. $Y$ es indudable y comprensible que se teman, porque cambian, diría, radicalmente todo el misterio de la gracia en el hombre, y concretamente de la justificación. Además, como de ordinario se ha ido a $\mathbf{S}$. Agustín a través del Concilio de Trento, se ha tratado de buscar en él textos comprobatorios del decreto de Trento sobre la justificación. De hecho si repasamos la bibliografía sobre la gracia y la predestinación, nos percatamos de que se dirige a otros problemas tal vez más tardíos en la historia de la teología, y se han proyectado sobre san Agustín ${ }^{1}$.

$\mathrm{Y}$ sin embargo la exposición que aquí se hace la creo fundamental para comprender a san Agustín, en especial su controversia antipelagiana. Su explicación arranca de aquí y aquí estribá. Posiblemente no podamos datar bien este libro VIII De Trinitate ${ }^{2} \mathrm{e}$

1. Serla inútil que nos dedicáramos a recoger aquí toda la bibliografía sobre la gracia en San Agustín. Remitimos sencillamente a algunas obras de interés para esta nota concreta, cfr. por ejemplo, H. RONDET, La théologie de la gråce dans la correspondance de saint Augustin, "Recherches Augustiniennes" I (1958) 303-315; A. NIEBERGALL, Augustins Anschauung von der Gnade. Ihre Entstehung und Enwicklung vor dem pelagianischen Streit (bis zum Abschluss der Confessiones), Gôttinguen, 1951; G. HOK, Status gratlae, en studie i Augustini etik, (Uppsala) 1954, inédito, vid. Augustin und die antike Tugendlehre, "Reryma und Dogma" 6 (1960) 103-130; M. P. Löhrer, Der Glaubensbegriff des hl. Augustinus in selnen ersten Schriften bis zu den Confessiones. Einsiedeln-Zürich-Köln, 1955; R. SCHNEIDER, Principium omnium Deus. Zum 1600-jăhrigen Augustinus publläum, "Für Arbeit und Besinnung" (Norddt. Beilage) 7 (1954), 334-343. Y en especial para los textos sobre la gracla y la predestinación con bibliografla, vid. J. CHENE, La Theologle de saint Augustin: Grace et Prédestination, Le Puy-Lyon, 1961.

2. Para una breve sintesis de la cronologia de la obra, vid. E. HENDRIKX, Introductlon, en "Oeuvres de saint Augustin" 15, 2me. Sérle: Dieu et son oeuvre :La Trinlté (libres I-VII) 1. Le Mystére. Texte de l'édition bénédictine, traduction et notes par M. Mellet et Th. Camelot, Paris 1955, 12-13 y en la nota complementaria 2, titulada: La date de composition du De Trinitate (pp. 557-566); L. ARIAS, Introducción, "Obras de San Agustín": Tomo V, Tratado sobre la Santísima Trinidad, Madrid, BAC, 1948, pp. 26-27. 
interesaria por la coincidencia o menos con las obras antipelagianas. A lo sumo que podríamos decir es que se trataría de los primeros años de la controversia, al menos en su última redacción. El comentario no siempre ha sido adherente al texto y se ha mantenido en un ángulo de visión demasiado estrecho. Queremos entonces seguirlo paso a paso y dejarle hablar a él, con la posibilidad de excraer luego las conclusiones pertinentes.

\section{Hacerse bueno}

S. Agustín parte de un supuesto ya adquirido para él y que no es necesario que probemos aquí ahora a través de toda su obra ${ }^{3}$. Se trata de una impresión divina, que es iluminación ontológica, manifestada por medio de un ansia, de un deseo profundo de los valores impresos. Esa impresión es gratuita, es indebida. Dios no podía dejar al hombre como a cualquier otro ser de la naturaleza. $Y$ no lo ha dejado, no por merecimientos del hombre, sino por libre amor suyo. Le ha ofrecido la impresión iluminante y el hombre tiene ya una gracia inicial, ontológica, inconsciente, habitual, punto de enganche con el Eterno 4 . Esto mismo cambiaría ya el sentido de algunos textos de la tradición cristiana y de la teología, que lo habría interpretado todo de modo extrinsecista.

El camino que Agustín recorre en este libro se nos antoja familiar en toda su obra. Dios es la verdad, y cuando al hombre se le dice "verdad", "primo ictu diluxit tibi", pero no puede permanecer en ella - manere-, en esa primera coruscación intuitiva, y vuelve a 10 habitual, a las manchas acostumbradas de la peregrinación ${ }^{5}$. Y 10 mismo le sucede con el bien, que es lo que al presente le interesa: "Mira de nuevo, si puedes. Ciertamente no amas sino lo bueno o el bien, pues buena es la tierra... Bueno es esto y bueno es aquello: prescinde de los determinativos esto y aquello y contempla el Bien puro, si puedes; entonces verás a Dios, Bien imparticipado. Bien de todo bien". Sin embargo no podríamos juzgar del bien de los seres, "si no tene-

3. Cf. J. MORAN, La teoría del conocimiento en san Agustin. Enchiridion sistemático de su doctrina, Valladolid 1961 con amplia bibliografia.

4. LOPE CILLERUELO, La "memoria Del" según san Agustín, "Augustinus Magister" 1, 499-509, París 1954; ID., ¿Por qué "memoria Dei"?, Revue des Études Augustiniennes" 10 (1964), 289294; ID.,Pro "memoria Dei, "Revue des Études Augustiniennes" 12 (1966); 65-84; G. MADEC; Pour et contre la "memoria Dei", "Revue des Etudes Augustiniennes" 11 (1965), 89-92; J. MORAN, Hacia una comprensión de la "memoria Del" según san Agustín, "Augustiniana" 10 (1960), 185-234; ID., Sobre le "memoria Del" agustiniana, "Augustinus" 9 (1964), 205-209; vid. nota 3; M. N. CASTEX, La memoria metafísica según el libro X de las "Confesiones", "Sapientia", 19 (1964), 9-25.

5. De Trin. VIII, 2, 3. PL 42, 949 
mos impresa en nosotros la noción del bien, según el cual aprobamos esto y lo anteponemos a otra cosa. Asi ha de amarse, pues, a Dios, no éste o aquel bien, sino el mismo Bien". En esto se da ya como una adquisición humana que la práctica y la experiencia vivencial ontológica manifiesta y demuestra. Podemos interrogar a todos los hombres y nos responderán en positivo, aunque quizá con una definición diferente de bien, pero saben apreciar en las personas cuál es lo bueno y cuál lo no bien hecho. No se trata ya de buscar el bien para juzgar de la bondad de las cosas o de las personas únicamente, sino el bien al que pueda adherirse la persona humana-cui haereat amando- Es un bien no para juicio, sino para goce, para hacerse uno bueno amando, y ése es Dios, al que llamamos "Bonum omnis boni".

Prosiguiendo el análisis, el descubrimiento de ese bien que nos hará buenos, es preciso distinguir dos cosas, que sirven para cualquier tipo de personas. El espíritu, o si se quiere, siguiendo la terminología de Agustín, el ánimo, o significada en él la persona humana que es buena, tiene dos cosas: una, "quo animus est" y otra, "quo bonus est", una por la que es ánimo, espíritu o persona, y otra, por la que es buena. Para ser ánimo no hizo nada, no lo mereció. La creación es indebida y gratuita, puro efecto del amor de Dios, es gracia, es un don, -non enim iam erat quod ageret ut esset- En cambio para que el ánimo sea bueno, es necesario que actúe, que trabaje y se esfuerce para hacerse bueno -ut autem sit bonus animus, video agendum esse voluntate-. Es ya bueno por el hecho de ser ánimo y es superior al cuerpo, pero lo es naturalmente, se diria, como son buenos todos los demás seres de la creación en sus diferentes grados. En cambio, para ser ánimo bueno, requiere la acción de su voluntad, por la que sea más excelente - restat ei actio voluntatis, qua sit praestantior-. Se le exige una obra personal, un esfuerzo, un empeño, personalizar el bien, de suerte que no sea sólo creacional sino que sea también personal, cooperando así a la propia "bonificación". Y para realizar esto y conseguirlo, solamente le queda convertirse a algo que no sea él mismo. $Y$ ese algo es el Bien que ama, apetece y logra. Si, por el contrario, se aparta de él y se hace no bueno, para poder convertirse a él enmendándose con el fin de hacerse bueno de nuevo es preciso que permanezca en él ese bien que ama y apetece - nisi maneat in se illud bonum unde se avertit, non est quo se iterum, si voluerit, emendare convertat-'.

6. Ib. VIII, 3, 4, PL 42, 949-950. 
El bien estaba impreso en la intimidad, está presente en ella, y permanece allí, y convirtiéndose a él conscientemente, voluntariamente, personalmente el hombre se hace bueno. Si le falta esa conversión mental, cordial y realizadora, el bien continúa en la intimidad, pero la persona no es buena, porque no vive consciente y a través de sus obras el bien. Esto mismo nos abre el abanico de la conversión a un auténtico sentido de la misma y nos ayuda a comprenderla, no solamente ya desde un aspecto platónico, sino desde una vivencia profundamente cristiana, que no queda sólo en lo intelectual y cordial, sino que exige la realización práxica. Entonces, siguiendo el proceso, prescindiendo o abstrayendo de los bienes relativos, aunque sean actuados, se llega al Bien supremo y se llega a él en la propia intimidad, poniéndose así en contacto con él, sabiendo, cuando cree, que ese Bien es Dios:" si puedes, pues, extraídos esos bienes, mirar el bien por sí mismo, mirarias a Dios. $\mathrm{Y}$ si te adhirieras -inhaeseris, es algo más, más íntimo, más profundo- por amor, al instante quedarías hecho feliz". Así puede ya comprenderse cómo se hace el ánimo bueno y feliz, no por algo sobreañadido a él, o que se le aplica o se crea en él, sino precisamente por la conversión hacia ese bien que está en la intimidad, en su ser más profundo y que no se aparta de la persona, aunque ésta se aparte de él. $Y$ por tanto "el ánimo para ser bueno se convierte a aquel, de quien procede su ser de ánimo", y es el "arte por el que fue hecho".

He ahí el punto de intersección entre la naturaleza y la persona, entre 10 "natural" y lo "sobrenatural" en el hombre, si bien no cuadran mucho estos dos nombres para lo significado por la exposición agustiniana. Uno mismo es el Bien que da el ser al ánimo y el que le permite, convirtiéndose a él, hacerse bueno. $Y$ entonces ya comprendemos que convertirse a ese bien es darse cuenta de él, tomar consciencia de él, quererlo conscientemente, amarlo y realizarlo luego en bienes o bondades concretas. Se trata, en última instancia, de unificar la naturaleza en el pleno sentido agustiniano ${ }^{7}$ y la voluntad. aue sería la manifestación de la persona. Así aparece con cierta evidencia que la voluntad o la persona, en nuestra manera de verlo, perfecciona la naturaleza al coincidir conscientemente con ella y hacerla personal, elevándola al nivel de la consciencia, de la responsabilidad y de equilibrio. "Y es entonces cuando la voluntad se compagina con la naturaleza para perfeccionar el ánimo en el bien,

7. Cf. Retract. I. 10 3. PL 32, 600: Item in eo quod paulo post dixi. Nullum esse malum naturale (De gen. c. Manich. II, 29, 43), possunt quaerere similem latebram, nisi hoc dictum ad naturam talem referatur, qualis sine vitio primitus condita est: ipsa enim vere ac proprle natura hominis dicitur; vid también Retract. $1,15,6, \mathrm{PL} 32,610$. 
cuando se ama aquel bien con la conversión de la voluntad; de donde procede también aquel que no se pierde ni por la aversión de la voluntad", es decir el bien que ha dado el ser al ánimo. Lo esencial, pues, será hacer coinciđir el deseo consciente con el "natural" para lograr el perfeccionamiento en una conquista personal. No son dos bienes distintos, ni tienen una finalidad diversa, sino que es uno só10. $Y$ al apartarse del sumo bien, el ánimo deja de ser "ánimo bueno", pero de ser "ánimo" que es ya un bien no ceia nunca, ya que "pierde la voluntad, lo que la voluntad conquista. Ya existía el ánimo que quisiera convertirse al bien del que procedía; sin embargo quien quisiera ser antes de ser aún no existia".

Una vez que Dios ha colocado en la persona la noción de la bondad o del bien y ha creado la voluntad o mejor el querer para poder hacerlo propio y personal, y entonces lograr la bondad o hacerse bueno es empresa personal. Así se mantiene fijo cuanto esto significa: es gratuito, porque se ha dado sin que pudiera exigirse ni quererse, haciendo así el espíritu humano, y a su vez en la impresión aparecen los valores, que atraen desde dentro para que se hagan personales. Dios lo ha puesto todo y ha dejado al hombre la libertad para que se decida libremente a hacerse bueno por visión o consciencia y por realización. "Y éste es nuestro bien donde vemos si hubiera debido o deba existir, cuanto comprendemos que ha debido o que debe existir; y donde vemos que no hubiese podido existir si no hubiese debido existir, cuanto no comprendemos cómo hubiese debido existir. Dicho bien no se halla lejos de cada uno de nosotros: En él vivimos, nos movemos y somos' (Act. 17,27-28)" ${ }^{8}$. La presencia de ese bien en la intimidad humana puede manifestarse en las aspiraciones de todos los hombres, mostrándolo la experiencia vivencial de la humanidad entera 9 . Estando presente en la intimidad de la persona e intuido de algún modo por ella, pues de lo contrario no se podría juzgar de él ni interna ni externamente, "es necesario permanecer cabe El y adherirse a él -inhaerere - por amor, a fin de gozar de la presencia de aquel de quien procedemos, con cuva ausencia no podriamos ni ser" 10. Ahora no lo vemos, siendo ese Bien supremo Dios, pero 10 amamos por la fe - per fidem-, pudiendo fingir de él lo que no es y entonces todas las virtudes irian erradas ${ }^{11}$.

\footnotetext{
8. De Trin. VIII, 3, 5, PL 42, 950.

9. Cf. J. MORAN, La teoria del conocimiento en San Agustin, Valladolid 1961, pp. 60-147.

10. De Trin. VIII, 4,6, PL 42,951. 752-753.

11. Desarrolla más ampliamente este argumento en VIII, 4, 7, PL 42, 751-752; 5, 7-8, cols.
} 
¿Cómo se ama lo que no se ve, o lo que se cree?

Hasta aquí pretende llegar Agustín y continuará su análisis. Ese Bien supremo que es Dios no se le ve cara a cara y podemos siempre pensar de él lo que no es. ¿Cómo entonces hacernos una idea de ese ser que está tras nuestro querer y que es lo que queremos y a lo que aspiramos fontalmente, aunque sea sin consciencia? He aqui el problema y Agustín así lo plantea: "La cuestión estriba en saber de qué semejanza o comparación de cosas conocidas nos servimos para creer en Dios, a quien amamos aun sin conocerlo" ${ }^{2}$. Había ampliado el argumento en lo precedente y éste era el punto que le quedaba en discusión y que era básico para una vida cristiana de fe. Es necesario comprender de algún modo cómo amamos a Dios aún sin conocerlo, creyendo en él, y considerar que lo amamos, al amar otros bienes, ya que no podríamos amarlos si no le amáramos a El que es el amor. La transcendencia de este nensamiento abre horizontes insospechados. En cada uno de nuestros actos de amor a los valores. bien, justicia, verdad etc.- estamos amando a Dios. aún no conocido, pero lo amamos creido, porque es a El a quien amamos, ya que sin El no podriamos amar, porque El se identifica con el Amor. $Y$ el amor a lo visible bueno y justo no es más que signo del Amor sin el que no podriamos amar.

Agustín está interesado en este argumento. $\mathrm{Y}$ tiene razón para ello. ¿Cómo se ama una cosa o una persona que no se conoce en sí misma, pero en la que se cree? ¿Se ama en sí misma y por sí misma, o más bien se ama en aquello que la visibiliza y tras lo cual continúa en el misterio lo creido o la persona en quien creemos? Si antes ha tratado de ver cómo se hacia uno bueno, ahora, prosiguiendo el argumento, examina otro hecho de experiencia. San Agustín iniciará de este modo: Hay quien ama al apóstol Pablo y lo ama porque tiene un "ánimo justo". No le ofrece dificultades el que ame el ánimo, pues éste puede conocerlo cada uno en sí mismo por una experiencia interna. Aclarando este primer término, se pregunta por lo de “justo" y aquí comienza nuevamente la gran disquisición: "Y ¿cómo o de dónde conocemos oué es ser justo, si aún no somos iustos?" La paradoja parece evidente. Sin embargo todo hombre busca la justicia y quiere ser iusto, aun cuando no lo sea, amando en su intimidad al hombre que es justo. $\mathrm{Y}$ si ama y busca al hombre justo o al ánimo justo, conoce lo justo de alguna manera, ya que no podria amarlo si no conociera ợé es ser iusto, "según lo que hemos demostrado

12. Ib. VIII, 5, 8, col. 953 . 
-escribe Agustín-, que nadie puede amar lo que cree y no ve, sino es por alguna regla de un conocimiento general o especial - nisi ex aliqua regula notitiae generalis sive specialis... En nosotros, pues, conocemos qué es justo, no en el cuerpo ni en algo exterior, sino "cabe mí mismo" ${ }^{13}$. Lo "justo" no es algo exterior, ausente de nosotros, sino que está dentro, presente en la intimidad. $Y$ lo prueba con ejemplos: "Cuando digo y lo digo conscientemente: 'Justo es el ánimo que distribuye a cada uno lo suyo con conciencia y razón en su vida y costumbres', no pienso en una cosa ausente..., sino que intuyo algo presente y lo intuyo cabe mí mismo, aunque yo no soy lo que intuyo, y si lo oyen muchos lo aprobarán". Y también quien lo aprueba conscientemente, lo ve cabe sí mismo, viéndolo no sólo el que es justo, sino también quien es injusto, o quien no es justo.

Lo maravilloso es precisamente esto: que también quien no es justo, ve la justicia y distingue, aunque no sepa definirlo, qué o quién es justo. ¿Qué ve entonces? "¿O es que lo que ve, es la verdad interior presente en el espíritu que es capaz de intuirla? Pues no todos son capaces, y aun los que pueden o son capaces de intuirla, no todos son lo que ven..." Se trata entonces de hacer que todos sean justos, dado que todos, tanto quienes no lo son como quienes lo son, son capaces de ver la justicia en sí mismos y en los demás. ¿Cómo se harán, pues, justos? Estamos un poco en la pregunta sobre cómo se harán buenos: Agustín ha llegado a profundizar aqui en un misterio que siempre se ha tenido en cristiano y casi nunca se ha tenido en cuenta. Los consejos, los preceptos, las exhortaciones a amar a Dios, a amar lo que no se ve, o a Aquel en quien se cree, son apremiantes para todo cristiano. $\mathrm{Y}$ sin embargo al cristiano nunca se le ha puesto en claro cómo puede amar a la persona que no ve y en la que cree. La gran cueja ordinariamente es ésta. Y hoy es más sentida que nunca. Tal vez el punto clave del mismo cristianismo actual venga solucionado por Agustin aquí, penetrando en hondura en este hecho: nadie ama algo que no ve o a alguien en quien cree, sino es por una noción general o especial impresa en su espíritu. $Y$ la vía de la búsqueda ha de ir por este camino de lo humano, ya que en nuestra ingenuidad cristiana hemos apelado con frecuencia a amar a aquel en quien creemos y a quien no vemos, pero no se le ha amado porque no se le ve. $v$ no se ha tratado de descubrix aquello nor lo oue se podría ver aquel en quien se cree. Es necesario, por tanto, dejar constancia de estos hechos que son de expreriencia universal profunda,

13. Ib., col. 954 . 
y por lo mismo se han calificado de ontológicos humanos, al descubrir que si todos los hombres aman el bien y aman la justicia, sean o no sean buenos y justos, conocen de algún modo, impreciso, inconsciente, por conocimiento ontológico humano, diría, qué es ser bueno y qué es ser justo. Si esto queda asegurado, podremos continuar la búsqueda y preguntarnos de nuevo:

¿Cómo se hace uno justo, una vez que cada uno ha intuido en sí mismo la noción de justicia impresa en él, o la presencia de la justicia en la propia intimidad? No de otro modo -contestará San Agustín- que "adhiriéndose a la forma que intuyen" -inhaerendo ipsi formae quam intuentur- y realizando en su vida el significado de la justicia que intuyen, "no pudiendo adherirse a ella más que amando" -unde inhaeretur illi formae, nisi amando?"- ${ }^{14}$ Antes, como hemos visto, se hacía el espiritu bueno, convirtiéndose y adhiriéndose al bien que estaba presente en la intimidad, a la forma del bien que había sido impreso, es decir a Dios que estaba presente y sin el que no podríamos vivir, que era sostén de la propia existencia. Ahora se hace justo el hombre del mismo modo, uniéndose a la forma que se ve en la intimidad y adhiriéndose a ella conscientemente por amor, manifestándola luego en la vida. $Y$ aquí surge de nuevo una pregunta que nos hace avanzar en el argumento, buscando aquello que vemos y que nos permita descubrir que amamos lo que no vemos o a aquel en quien creemos. Si uno se hace justo, amando la forma en que vemos qué es ser justo, ¿por qué amamos el ánimo justo y no amamos esa forma "en que vemos qué es el ánimo justo?" ¿O es que amamos el ánimo justo, pero lo amamos "por esa forma - ex ista, la fuerza de ese ex que nos ha aparecido ya en otros textos es intraducible al español, pero indica procedencia y origen-, pero mientras no somos justos, la amamos menos de lo que seria necesario para ser capaces de ser justos"? Esta sería la verdad. $Y$ entonces por lo que se ve $y$ en lo que se ve en la intimidad y por la realización de la justicia en el hombre justo a quien amamos, nos percatamos de que amamos la forma que hace justo, pero que no se ve y en la que creemos. La respuesta a nuestra pregunta coincide con la conclusión de Agustín a todo este examen: "El hombre que es creido justo, es amado por aquella forma y verdad -ex ea forma et veritate - que ve y entiende cabe si aquel que ama; en cambio no existe otro modo de amar aquella forma y verdad. Pues no hallamos algo tal fuera de ella misma que lo amemos creyendo,

14. Ib., col. 955. 
cuando es desconocido, por el hecho de conocer ya algo semejante. Cuanto vieres tal cual, es ella misma; y no existe otra cosa tal, porque sola ella es tal, cual ella es". $Y$, por tanto, a los hombres hay que amarlos o porque son justos o para que sean justos, y así tendremos que amarnos a nosotros mismos y los amaremos como a nosotros mismos.

La justicia solamente puede amarse de este modo en su realización y viéndola realizada en personas concretas y en sus situaciones la amamos, pero a ella no la vemos, sino que creemos en ella, descubriendo su presencia íntima en lo realizado. Sólo de ese modo no se esfuma ni se azota al aire, a la hora de un amor puramente espiritualizado, ya que entonces nuestro amor a la justicia nace también de una fe, fundamentada en una visión. Pienso que todo el problema está aquí resuelto: se ama al hombre justo por la forma o la verdad que se ve y entiende en la intimidad quien lo ama, y ama la justicia que no ve y en la que cree por la justicia que ve. La justicia o la verdad o la bondad aparece en la realización y se ama en su manifestación, que descubre que detrás está presente ella. Sería el modo de amar una cosa o una persona que se desconoce, pero en la que se cree, y se cree en ella porque existe algo que se ve y se entiende, pero no se explica por sí mismo, sino que detecta algo más íntimo y superior ${ }^{15}$. Esta conclusión es de capital importancia: lo invisible, lo espiritual, aquello que no se ve y en lo que se cree, solamente puede ser amado en sus realizaciones, a través de las oue mostramos oue se ama lo espiritual sin cuyo amor no se amaria esto concreto.

He aquí entonces la gran conclusión para el misterio de la gracia: Solamente se ama el amor amando, porque amando manifestamos el amor que no se ve $y$ en el que se cree $y$, creyendo en él, se ama por lo que se ve. Si el amor es el que nos hacía adherir a la forma de la justicia o de la bondad, haciéndonos de este modo justos y buenos, ¿cuál es el verdadero amor? "Esta es la verdadera dilección que, adhiriéndose a la verdad, vivamos justamente: y en consecuencia, despreciemos todas las cosas mortales por el amor de los hombres, por el que queremos que vivan justamente. Así podremos estar preparados también a morir por nuestros hermanos, cosa que nos enseñó nuestro Señor Jesucristo con su ejemplo". El amor a los hombres es básico y por ellos es preciso estar dispuestos a morir, ya que a través de ese amor manifestamos que amamos a Dios, que existe y actúa Dios en nosotros, que está presente activamente en nuestra

15. Ib., VIII, 6, 9, cols. 954-956. 
intimidad. Así nos da lo mismo que la Escritura nos hable sólo del "amor de Dios" o del "amor del prójimo", ya que si habla del primero, "también quien ama a Dios es lógico que haga lo que Dios manda, y en tanto ama en cuanto lo hace; es lógico, por tanto, que ame también al prójimo, ya que esto lo mandó Dios"; y si habla del segundo, "también por esto, ya que quien ama al prójimo, es lógico que ame primordialmente la misma dilección o amor. Dios es amor, y quien permanece en el amor, en Dios permanece" (1 Jo 4,16). Es lógico, pues, que ame primordialmente - praecipue- a Dios" ${ }^{16}$. Y para buscar a Dios, no hay que abandonar "la propia interioridad, más interior que la cual es Dios" ni dedicarse a la vanidad y a la altivez de poder. "No goza el santo de este su poder, sino del poder de aquel de quien tiene el poder de poder cuanto congruentemente puede; y sabe que es más fuerte el unirse - coniungi- al Omnipotente con niadoso cuerer, que poder por propia voluntad y potestad aquello que haga temblar a quienes no pueden tales cosas".

Se nos llama a la propia intimidad y el mismo Cristo nos ha vocado a ella, "apartándonos del estrépito exterior hacia los gozos silenciosos". "He aquí que Dios es amor: ¿a qué vamos y corremos a las alturas de los cielos y a las profundidades de la tierra, buscando a aquel que está cabe nosotros, si nosotros queremos estar cabe él?" Dios está presente en nosotros y está presente como amor, como justicia, como bondad. Quien ama, pues, al hermano, ama el amor y ama a Dios que es amor, y entonces "ame al hermano, y amará la misma dilección o amor. Más conoce el amor con que ama, que al hermano a quien ama. He aqui que puede ser más conocido para él Dios que el hermano: ciertamente más conocido, porque más presente; más conocido, porque más interior; más conocido, porque más cierto. Abraza al Dios amor y abraza a Dios por amor. Este es el amor que consocia a todos los ángeles buenos y a todos los siervos de Dios con el vínculo de la santidad, y a nosotros y a ellos nos une mutuamente - conjungit - y nos somete a si -subjungit-. Cuanto más sanos estemos de la hinchazón de la soberbia tanto más llenos estaremos del amor: y ¿de qué está lleno, sino de Dios, quien está lleno de amor?" 17.

La caridad se ve y se contempla con la mente, cuando se la ve realizada, y si se ve la caridad o el amor, no sólo se ve a Dios, sino que se ve la Trinidad, "más aún ves la Trinidad, si ves la caridad". La caridad que no ama no es caridad -charitas enim non est quod

16. Ib., VIII, 7,10 , cols. 956-957.

17. Ib., VIII, 8,12 , col. 957 
nihil diligit-, o como dirá también, "donde no se ama nada, no hay amor" - ubi nihil amatur, nullus est amor- ${ }^{18}$. La caridad es, por consiguiente, siempre activa, dinámica, no es estática, no hay, diriamos, un estado de caridad, sino un amar constante. La misma caridad para amarse a sí misma tiene que amar algo, ya que manifiesta su existencia en el amor y no puede saber si existe, si no ama. "Asi la caridad se ama ciertamente a sí misma, pero si no se ama a sí misma amando algo, no se ama como caridad. ¿Qué ama la caridad, sino lo que se ama con caridad?" El amor no existe sino amando, no es un algo que se deposita, una cosa más que se almacena y que se pondrá en marcha. Es amor porque ama y amando sabe que es amor. $Y$ como la caridad para amarse manifestándose que existe, tiene que amar algo, comenzando desde el amor al prójimo, ama siempre a un hermano ${ }^{19}$. Por eso la caridad fraterna viene recomendada en grado sumo en la Escritura, que hace consistir la "perfectio justitiae" en la caridad fraterna y "en ella quiere dar a entender a Dios". Y recogiendo la $I$ Jo. 4 en la que "caridad fraterna o dilección fraterna viene definida como el amor por el que nos amamos mutuamente", dirá que "es predicado por tan grande autoridad que no sólo procede de Dios - ex Deo-, sino que es también Dios. Cuando, pues, amamos al hermano a impulsos del amor, amamos al hermano a impulsos de Dios: y no puede acaecer que no amemos primordialmente el mismo amor, por el que amamos al hermano" ${ }^{20}$. El pensamiento no nuede desvirtuarse $\mathrm{y}$ se requiere ir al fondo del problema. dada la trayectoria del pensamiento de Agustín. Se suele anelar aquí al platonismo de Agustín, a la teoría de la narticinación. Sin embargon tengo para mi que Agustín es preciso en sus afirmaciones. como lo será en la Exposición a la Epistola de san Juan ${ }^{21}$. Es Dios mismo presente en el fondo más radical del hombre y no una varticinación creada de El, aue seria diversa para cada uno. No habria un ser creado en nosotros que sería amor o caridad, sino que la realización

18. Ib., IX, 2,2, col. 962 .

19. Ib.

20. El texto latino dice: "non solum ex Deo, sed etiam Deum esse tanta auctoritate praedicari. Cum ergo de dilectione diligimus fratrem, de Deo diligimus fratrem; nec fieri potest ut eamdem dilectionem non praecipue diligamus, qua fratrem diligimus". La teología tradicional se ha opuesto a la interpretación de Pedro Lombardo. En nuestro tiempo se ha apelado a la interpretación agustiniana de la participación platónica. Todo el problema nacia del buscar en el hombre también una caridad creada, participación, por tanto, de la caridad divina. Sin embargo en el pensamiento agustiniano es la misma presencia de Dios en cuanto caridad lo existente en el hombre y no veo la necesidad de un nueva creación como de una cosa más que se "pegara" al hombre. A pesar de todo, quizá con interpretación distinta, yo dirla que los textos agustinianos dan la razón a Pedro Lombardo.

21. Cf. J. GALLAY, La cherite fraternelle selon les Tractatus in Primam Joannis de saint Augustin (Thèse de doctorat, fac. Cath. Théol. de Lyon), Lyon 1953, pro manuscripto; ID., La conscience de la Charité fraternelle d'après les "Tractatus in Primam Joannis" de saint Augustin, "Revue des Études Augustiniennes" 1 (1955) 1-20. 
del amor en la caridad fraterna manifiesta claramente la presencia actuante de Dios que es el amor que amamos, revelado en el amor a la persona que vemos, por la que amamos a Dios presente que no vemos y en el que creemos por ese amor sin el que no podríamos amar. Agustín continua abundando en el mismo pensamiento y en el modo de ver a Dios en el amor fraterno. No estando el hombre en el amor, no está en Dios y no está en la luz y como Dios es luz, no ve la luz y está entonces en tinieblas. Al hermano lo ve "con mirada humana", pero a Dios no puede verlo así. "Pero si a aquel a quien ve con mirada humana, lo amase con caridad espiritual, vería a Dios que es la misma caridad, con la mirada interior con la que puede ser visto. Así pues, quien no ama al hermano a quien ve, ¿cómo puede amar a Dios, a quien no ve, precisamente, porque Dios es amor, del que carece quien no ama al hermano?" Es comprensible: la caridad sólo se ama, cuando se ama a alguien a quien se ve y sino, la caridad no existe, aunque exista en la intimidad Dios como presencia, pues su presencia como caridad no ha sido manifestada en el amor. La caridad es única y la misma por la que amamos a Dios y al prójimo, aunque sea el motivo distinto, a Dios por Dios mismo, y a nosotros y al prójimo por Dios ${ }^{22}$.

El ejemplo que nos había propuesto al principio era el del amor al apóstol Pablo, porque era justo. $Y$ vuelve al final al mismo, citando ampliamente 2 Cor 6, 2-10. Dirá que amamos al Apóstol porque creemos que vivió así y agrega: "Que han de vivir así los ministros de Dios, no lo creemos oído de algunos, sino que lo vemos interiormente en la misma verdad cabe nosotros mismos o sobre nosotros mismos. A aquel, pues, que creemos que ha vivido así, lo amamos por lo que vemos -ex hoc quod videmus-. Y si no amásemos primordialmente esta forma que vemos siempre estable e inconmutable, no lo amariamos precisamente porque retenemos por fe que su vida, mientras vivía en la carne estaba coaptada y conformada a esta forma". Y así "la fe sirve para el conocimiento y el amor de Dios, no como del todo desconocido, o del todo no amado; sino para ser conocido con más claridad, y amado con más firmeza" ${ }^{23}$. La caridad, en consecuencia, o la dilección es "amor boni" y "el amor es de algín amante. $v$ nor el amor se ama algo. He aouí, pues, tres cosas: el amante, lo que se ama y el amor. ¿Qué es el amor, sino una vida que une o desea unir dos cosas, a saber el amante y lo amado?" ${ }^{24}$. Se-

\footnotetext{
22. De Trin. VIII, 8, 12, PL 42, 958-959.

23. Ib., VIII, 9, 13, cols. 959-960.

24. Ib. VIII, 10,14 , col. 960 .
} 
ria un vestigio o una imagen también de la Trinidad. Detrás del amante y del amado hay algo que existe y actúa y sin lo que no podría darse esa relación. $Y$ es la caridad que es Dios y que se trasluce y manifiesta en el amor realizado.

De esta suerte se ha hallado el modo de hacer ver cómo se ama a Dios aún no conocido amando a alguien que se ve y creyendo a través de ello en lo que no se ve. El hombre se hace justo y bueno, amando y adhiriéndose a la justicia y a la bondad, y ama éstas, amando y realizando lo justo y lo bueno. Lo hace personal, suyo, consciente, progresando de ese modo en la justicia y la bondad que ya tenía por creación. Era don y dádiva gratuita y necesitaba aceptarla conscientemente, haciéndola suya y aumentándola de ese modo. Justicia, bondad, amor es Dios y se manifiestan en la realización y nadie es justo sino por la justicia, nadie es bueno sino por la bondad, nadie ama sino por el amor. Todo esto es don y gracia, pues no se nos debía y se nos ha hecho presente sin merecimientos nuestros, llamándonos desde la intimidad con su atracción y sucitando una respuesta por parte nuestra. Es misteriosa y creemos en ella, porque aparece en lo que se ve, creyendo a través de lo visible realizado en el amor invisible. Es la presencia de Dios como amor, como justicia, como bondad, y es obra del hombre que personaliza esa presencia haciéndola consciente en visión interior y realización exterior. No es un nuevo elemento que se adiciona al hombre, sino la toma de conciencia, la personalización, por la realización, de que en el amor a los hermanos amamos el amor que es Dios y asi se concreta en una toma de conciencia de la presencia de Dios en nosotros, en quien creemos por el amor de lo que vemos, ya que nadie ama sin amor y el amor es Dios.

Se trataría de poner de acuerdo la "naturaleza" con la "voluntad" que identificábamos con la persona, el bien "natural" creacional con el bien libre y conscientemente conquistado. Uno y otro son dones de Dios, porque ese bien concreto que hace el hombre o esa justicia determinada o ese amor a una persona existe porque en la intimidad existe la presencia del Bien, de la Justicia y del Amor que es Dios, atrayendo al hombre hacia la realización. Así se desarrolla y se perfecciona la persona con sus valores puestos en práctica y en la misma obra revelan la presencia de Dios - gracia fontal- que es amor, justicia, bien. Negarse a amar, a hacer justicia, a hacer el bien, es ser malo, ser pecador, vivir en tinieblas, ser menos hombre, porque no se desarrolla lo creacional, amándolo libremente. Se manifiesta que no se ama a Dios a quien no se ve, cuando no se ama al herma- 
no a quien se ve, porque al no amar no se manifiesta a Dios como amor. Solamente a través del amor al hermano que se ve, se revela la caridad que no se ve y a Dios que se identifica con ella. Así se ama lo que no se ve, o a la persona en quien se cree.

Las consecuencias de estas reflexiones agustinianas son de la máxima actualidad y responde a la mayor parte de los interrogantes de nuestra historia presente. No queremos salir del marco agustiniano y cerramos aquí nuestro examen. Queda abierta al lector la posibilidad de una aplicación a los problemas teológicos más acuciantes.

José Morán 